\title{
Design of a Student's Online Examination System Based on B/S Architecture
}

\author{
Guizhen Wang \\ Network Information Center, Qilu University of Technology \\ Jinan, China \\ wgz@qlu.edu.cn
}

\begin{abstract}
With the development and popularization of computer network in science and education, the traditional way of examination with examination papers, answering mode and score management is undergoing tremendous change. To resolve the problem, a student's online examination system is designed and implemented. There are three modules (named administrator, teachers and students) in the students online examination system based on $B / S$ architecture. Functions such as system management, teacher user management, examination paper bank management and issue announcement are belonging to the administrator module. The function of the teacher module includes teacher information maintenance, student account management, exam management module, examination paper management, examination paper analysis, result statistics and so on. And the function of the student module includes student information maintenance, online examination, score query and other functions. Later practical application proved that the students online examination system can reduce the workload of teachers and improve the teaching efficiency.
\end{abstract}

Keywords - online examination; educational research, B/S

\section{INTRODUCTION}

Along with the application and popularization of Internet technology, our lives have become increasingly dependent on the network for computer networks inject a strong impetus to the development of society said as in[1,2]. Not only the enterprise but also the government and the education cannot do without the network. Online examination system as a new way of education has become an important research area for the traditional education method can not meet the needs of modern education said as in[3]. It is not difficult to see that in the near future, the way of online examination will gradually replace the traditional way of written examination. Compared to the traditional written examination, the new computer online examination system has many irreplaceable advantages said as in[5]. First, seen from the cost, it can not only make the marking workload be greatly reduced, but also greatly save investment. Second, with the computer network technology, it is more and more obvious that the application of emerging technologies will bring an increasingly obvious advantage. Third, the emerging online examination can bring an unparalleled effect in automated and systematic statistical analysis. The advantage is better especially in the case of a large number of candidates to participate in the examination. Compared to the previous, great progresses in long distance education have been made in our country. However, there are still large number areas using the traditional paper-based examination methods at present. Manual generating examination-paper, manual marking, manual performance evaluating and carrying examination are the 5 steps can not be omitted in a traditional examination. But with the development of the times and the adjustment of examination and requirements, it is no doubt that the traditional examination brings disastrous workload to teachers. So, due to the emerging technology injecting a strong vitality into the development of education, it is very clearly that the reform on the traditional examination mode is the inevitable with development of the times.

Currently, it is very meaningful to design and develop a practical online examination system said as in[6]. Not only requirements of paperless, networking and automation of the examination, but also the need of online learning, online testing are satisfied. And the users can timely learn and correspond for their shortcomings and mistakes, so the efficiency of selflearning is greatly improved. Efficiency is greatly improved by the online examination system because the work such as question database maintenance, examination paper generation, online examination, examination paper marking, and statistical analysis of the results is automatically completed. And teachers, freed from the tedious traditional examination work, can focus more attention on teaching. The main content is organized as the following: (1) In the introduction section, after analyzing the problems in the traditional examination work, an online examination system based on the $\mathrm{B} / \mathrm{S}$ architecture is introduced.(2) Development platform, development tools and technology such as working principle of the $\mathrm{B} / \mathrm{S}$ architecture, MyEclipse, and Spring framework are introduced in the second section.(3) The structure of the system, each function module and system database design are described in the third section.(4) The results obtained by the system are present in the last section.

\section{DEVELOPMENT PlATFORM}

\section{A. B/S architecture}

$\mathrm{B} / \mathrm{S}$ architecture is adopted by the students online examination system, and its working principle is shown in Fig. 1. The Web Browser, Web Server and Database Sever are three constituents of the $\mathrm{B} / \mathrm{S}$ architecture said as in[5]. Using Web Browser run on the client computer, users send the Web request to access the Database Sever with hypertext form to the 
Web Sever. Customer request accepted from the Web Browser will be converted to SQL syntax, and submitted to the Database Sever by the Web server. And then the Database Sever gets the request, verifies its validity, carries on the data processing, and returns the processed result to the Web server. The Web Sever again gets the results, transforms into HTML document form, and forwards to the client browser. At last the result will be shown to users with a friendly Web page.

In this way, only a very small part of the work will be implemented at the client browser, while most of the other work is performed on the background WEB server. The B/S architecture helps to reduce system consumption and maintenance cost as said in [6].

\begin{tabular}{|c|c|c|c|c|}
\hline Web & Web Req & Web & SQL Req & Databrese \\
\hline Browser & Recult & Server & Result & Sever \\
\hline
\end{tabular}

Fig. 1. B/S Architecture

\section{B. Development tool}

The students online examination system is run on computer with Windows series operating system. The Web Sever used by the system is Tomcat (version 6.0+). The Database Sever used by the system is MySql database (version 5.0+). And JDK(version 1.7.0) of Java is also used by the system.

One of the development tools used by this system is the MyEclipse(Enterprise Workbench MyEclipse), which is a most comprehensive IDE Java development tool and is an enterprise class work platform. In simple words, MyEclipse is an extension of Eclipse and a powerful J2EE integrated development environment. Another development tools used by this system is Spring Framework, which is an open source application framework for the Java platform. Spring framework contains 7 modules such as the core container, context, AOP, DAO, ORM, WEB and MVC framework. Spring as an open source middleware, is independent of a variety of application servers. Even without the support of the application server, Spring can provide the function of the application server such as declarative transaction, transaction processing and etc. Spring is committed to the solution of each layer of J2EE application and Spring is the one of best options for enterprise application development. The MySQL software delivers a very fast, multi-threaded, multi-user, and robust SQL(Structured Query Language) database server. MySQL Server is intended for mission-critical, heavy-load production systems as well as for embedding into mass-deployed software. The most import thing is that MySQL is the world's most popular open source database.

\section{DESIGN OF THE SYSTEM}

\section{A. Overall design}

The whole system is divided into three modules: administrator module, teacher module and student module. The administrator module do the functions of system management, teacher-user management, examination-question-library management and issue announcement; The teacher module includes maintenance of teacher information, student-user management, test management module, automatic organizing of examination-paper, examination-paper management, examination-paper analysis, result statistics and so on; Student module includes student information maintenance, online examination, score inquiries and other functions. The overall design is specified as shown in Fig.2

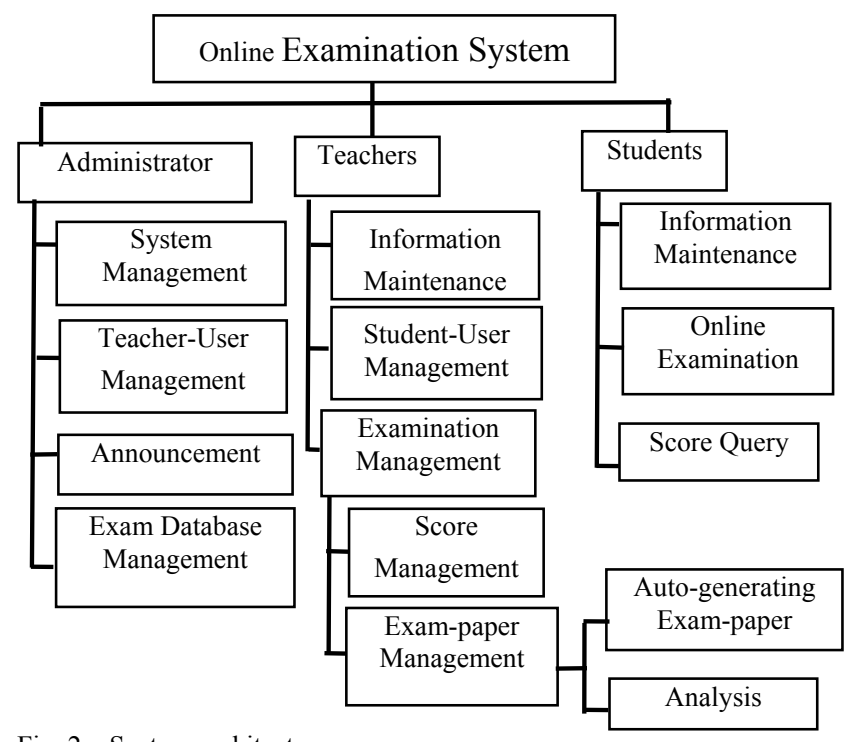

Fig. 2. System architecture

\section{B. Database design}

It is very important for the network examination system which needs a lot of data processing and data storage, to establish a simple and efficient database system. Prior to the establishment of the database, it is required to use the E-R diagram to study the relationship among the data entities.

An examination paper is composed by a certain number of questions while a question may be appeared in different papers. The E-R chart of examination paper and questions is shown in the Fig.3.

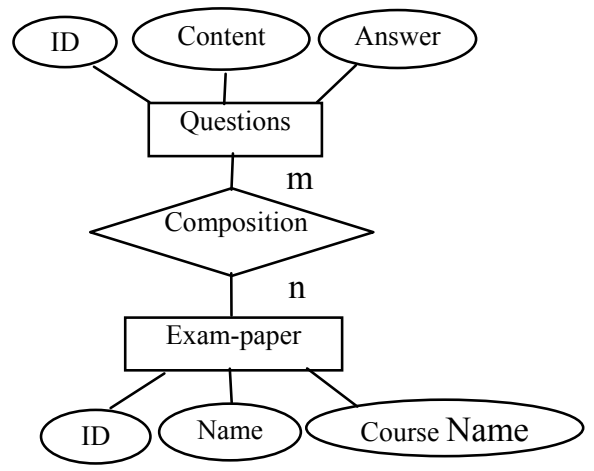

Fig. 3. Chart for exam-paper and questions

In relational database, table is a kind of important components. All data in a relational database are in the form of a table which is the basic object for it is always used to store data and operate data. Creating table is the base operation of database. In the database of online examination system, there are eleven tables such as administrators table(t_manager), teachers table 
(t_teacher), students table (t_student), course table (t_course), teaching course table (t_teach_course), professional class table(t_class), department table ( $\mathrm{t}$ _department), examination paper table (t_test), examination table(t_stu_test), examination question table ( $\mathrm{t}$ _questions) and knowledge table (t_point). Due to limited space, only a few key tables are presented in the following:

\section{1) Students table}

Students table (named t student) include the examination ticket number, name, password, sex, professional class, phone number, photos and other attributes as shown in Table 1.Among them, the self-increasing stu id with is set as the only primary key for the table to identify constraints, and ensure that each data content is not exactly the same. The cla_id field is set as the foreign key to the associated the cla i $\bar{d}$ field in the t_class table.

\section{2) Exam-paper table}

Students table (named t student) include the examination tic Exam-paper table (named t test) include the paper's identification number, the name of the examination paper, the subject, the examination date, the identification number of question library as shown in Table 2. Among them, the selfincreasing test id with is set as the only primary key for the table to identify constraints, and ensure that each data content is not exactly the same. The cou id field is set as the foreign key to the associated the cou_id field in the t_course table.The test_ques field is the collection to store all the identification number of examination question. A semicolon is used to separate every two single-choice questions. At the same time a comma is used to separate a single-choice question and multiple-choice question.

\section{3) Exam-paper table}

Examination question table include the identification number of examination question, type of question, question title, questions options, answers and etc. are shown in Table 3.

Among them, the self-increasing q id with is set as the only primary key for the table to identify constraints, and ensure that each data content is not exactly the same. The poi_id field is set as the foreign key to the associated the poi id field in the t_point table.

TABLE I. STUDENTS TABLE

\begin{tabular}{|l|c|c|l|}
\hline Fields & Data Type & Length & \multicolumn{1}{|c|}{ Comments } \\
\hline stu_id & varchar & 8 & Primary Key \\
\hline stu_name & varchar & 20 & Name \\
\hline stu_pwd & varchar & 10 & Password \\
\hline stu_sex & varchar & 2 & Sex \\
\hline cla_id & varchar & 20 & Professional Class Name \\
\hline school & varchar & 20 & School Name \\
\hline tel & varchar & 11 & Telephone Number \\
\hline photo & varchar & max & Photo \\
\hline
\end{tabular}

TABLE II. STUDENTS TABLE

\begin{tabular}{|l|c|c|l|}
\hline \multicolumn{1}{|c|}{ Fields } & Data Type & Length & \multicolumn{1}{c|}{ Comments } \\
\hline test_id & int & 4 & Primary Ke \\
\hline test_name & varchar & 50 & Name of the exam-paper \\
\hline cou_id & int & 4 & Course ID,Foreign Key \\
\hline test_time & date & 8 & Date of the examination \\
\hline test_ques & varchar & $\max$ & Collection of Question ID. \\
\hline
\end{tabular}

TABLE III. EXAMINATION QUESTION TABLE

\begin{tabular}{|c|c|c|l|}
\hline Fields & Data Type & Length & \multicolumn{1}{|c|}{ Comments } \\
\hline q_id & int & 4 & Primary Key \\
\hline q_type & int & 4 & Type \\
\hline q_title & varchar & $\max$ & Question title \\
\hline q_items & varchar & $\max$ & Questions options \\
\hline q_ans & varchar & 50 & Answer to question \\
\hline poi_id & int & 4 & Knowledge point \\
\hline cou_id & int & 4 & Course,Foreign key \\
\hline
\end{tabular}

\section{SUMMARY}

During actual teaching process, although certain fruits have been obtained in the students online examination system, there are still many aspects need to be improved for the urgent time and the designers limitations. However, with the development of science and technology, online examination will certainly be the trend of social development.

\section{REFERENCES}

[1] Zhang D, Wei Z, Yang Y. Research on Lightweight MVC Framework Based on Spring MVC and Mybatis [C]. Sixth International Symposium on Computational Intelligence and Design, pp.350-353, 2013.

[2] Z. J. Wang, X.F. Xu, D. C. Zhan, Inter-enterprise Integration Oriented Normalized Design Method for Web Services [J], Computer Science, vol.33,pp. 131-135, 2006. (In Chinese)

[3] Paulson, Linda Dailey. Building Rich Web Applications with Ajax[J]. Industry Trends Computer, vol.10, pp.14-17, 2014.

[4] Wu Xiaoqin, Song Yin. Research on Intelligent Auto-Generating Test Paper Based on Improved Genetic Algorithms[C]. Computational Intelligence and Software Engineering, CiSE 2009. International Conference, pp.1-4. 2009.

[5] J. Lei, Study of Role-Based Access Control in Permission Management [J], Journal of Hubei Automotive Industries Institute, vol.19, pp.50-52, 2010

[6] Zhou Guo Bing, Liu Ting Ting, Liu Xinxin. Algorithm and strategyresearch of generating test paper for large scale online examination[C].Electronic and Mechanical Engineering and Information Technology (EMEIT), pp.3285-3288,2011.

[7] Zhou Guo Bing, Liu Ting Ting, Liu Xinxin. Algorithm and strategyresearch of generating test paper for large scale online examination[C].Electronic and Mechanical Engineering and Information Technology (EMEIT), pp.3285-3288,2011. 